\title{
Dor Oncológica: Emergência Médica Mundial
}

\author{
Nedel, D.N.; Felin, F.D.; Felin, I.D.; Muller, G.H.; Nunes, T.F.; Fernandes, E.L.; \\ Apresentador: Débora Limberger Nedel
}

\section{Resumo}

Introdução: A dor é um fator determinante de sofrimento em relação à várias doenças, incluindo o câncer, onde pode causar até mais sofrimento que a própria expectativa da morte. A dor acomete de 60 a $80 \%$ dos pacientes com câncer, intensificando-se nos pacientes terminais. Diante disso, a Organização Mundial da Saúde declarou a dor oncológica como uma emergência médica mundial. Deste modo, difundir os conhecimentos sobre a dor oncológica, almejando máximo alívio, tanto através de analgésicos fármacológicos quanto por terapias intervencionistas, são atitudes indispensáveis no manejo adequado do paciente com câncer. Nos pacientes com câncer, o principal tipo de dor é a nociceptiva somática que, quando atinge estruturas nervosas, passa a ser também neuropática (comum em tumores de pulmão, próstata e mielomas). Geralmente as causas da dor oncológica se relacionam com invasão tumoral óssea e visceral derivadas das neoplasias, mas o próprio tratamento radioterápico e quimioterápico pode ocasionar a algia crônica referida. O alívio da dor no paciente com câncer é baseado no diagnóstico do mecanismo da dor, inflamatória, neuropática, isquêmica ou compressiva, e ainda no diagnóstico da síndrome dolorosa que mais prepondera. Para o alívio da dor, utiliza-se combinações de procedimentos que diminuam a massa tumoral como: cirurgia, radioterapia, quimioterapia, combinados aos fármacos analgésicos, como os opióides, os mais utilizados para o controle desse tipo de dor. A equipe envolvida, deve ser composta por oncologistas, fisioterapeutas, psiquiatras, enfermeiros e clínicos da dor, familiarizados com todas opções terapêuticas disponíveis. O sucesso do controle da dor ocorre quando se alcança o equilíbrio entre alívio da dor e efeitos colaterais. Métodos: Foi realizado um levantamento bibliográfico através da pesquisa em rede, juntamente com literatura atualizada e revisada sobre o tema da dor oncológica e seu tratamento e alívio. Resultados e Conclusão: Este trabalho visou reconhecer a dor oncológica como uma emergência médica, passível de manejo adequado, visando melhorar a qualidade de vida dos pacientes oncológicos. Neste sentido, foram alcançados os objetivos propostos, evidenciando-se efetivo valor do tema abordado, por contribuir na difusão do conhecimento sobre o tema abordado.

\section{Referência:}

Nedel, D.N.; Felin, F.D.; Felin, I.D.; Muller, G.H.; Nunes, T.F.; Fernandes, E.L.;. Dor Oncológica: Emergência Médica Mundial. In: Il Congresso Brasileiro de Medicina Hospitalar - II CBMH [= Blucher Medical Proceedings, vol.1, num.5] São Paulo: Editora Blucher, 2014. p.29

DOI 10.5151/medpro-II-cbmh-022 